\title{
American Recovery and Reinvestment Act and the Expansion and Streamlining of the National Health Service Corps: A Great Opportunity for Service- Minded Family Physicians
}

\author{
Donald E. Pathman, MD, MPH, Byron J. Crouse, MD, Luis F. Padilla, MD, \\ Theresa V. Horvath, PA-C, MPH, and Tam T. Nguyen, MD
}

President Obama has challenged Americans to improve their communities and country through service to others. ${ }^{1}$ There are many ways one can serve others but few ways one can do this and benefit financially from one's service. The National Health Service Corps (NHSC) offers physicians and others in health care a way to do exactly this. With a $\$ 300$ million expansion from the American Recovery and Reinvestment $\mathrm{Act}^{2}$ and an updating of its programs, the NHSC now offers more and better opportunities than ever for rewarding and well-compensated service.

The NHSC has long been the premier federal initiative directly supporting the primary health care practitioner needs of underserved communities. The 40-year-old NHSC's Scholarship Program, its longest running program, pays tuition and other education expenses for health professions students who contract to serve in designated high-need communities after their training. The NHSC's predominant current initiative is its Loan Repayment Program, which of-

This article was externally peer reviewed.

Submitted 16 June 2009; revised 16 June 2009; accepted 23 June 2009.

From the Department of Family Medicine and Cecil G. Sheps Center for Health Services Research, University of North Carolina at Chapel Hill (DEP); the Department of Family Medicine, University of Wisconsin, Madison (BJC); the Upper Cardozo Community Health Center, Unity Health Care, Inc, Washington, D.C. (LFP); the Physician Assistant Program, Hofstra University, Hempstead, NY (TVH); and Family Medicine Residency, San Joaquin General Hospital, Stockton, CA (TTN).

Funding: none.

Conflict of interest: All authors serve on the National Advisory Council of the National Health Service Corps.

Corresponding author: Donald Pathman, MD, MPH, Department of Family Medicine, UNC CB\# 7595, University of North Carolina, Chapel Hill, NC 27599-7595 (E-mail: don_pathman@unc.edu). fers a $\$ 50,000$ education loan repayment enticement to practitioners who have completed their training and serve for 2 years in eligible underserved areas. The full value of this enticement, which practitioners receive on top of their regular salary from the clinics where they work, is closer to $\$ 65,000$, because NHSC funds are exempt from federal income taxes and participants would otherwise have to repay their education loans with personal, after-tax earnings. This improves the starting annual salary for work in a health center from, for example, $\$ 110,000$ to a value of approximately $\$ 142,000$, making the option of work in an underserved area financially attractive for those carrying education loans. And the option to extend the loan repayment agreement for a third and fourth year and beyond for a $\$ 35,000$ loan repayment amount for each extended year makes the deal even more attractive. With loan repayment, service does not demand financial sacrifice of practitioners.

As of this past spring, 2950 NHSC clinicians were working in underserved communities, including 2394 who were receiving loan repayment support and 556 who had received scholarship support when they were students. ${ }^{3}$ In its early days, the NHSC limited its awards to the primary care disciplines and principally physicians. Now, its workforce has diversified to include mental health and dental health workers. However, primary care remains the NHSC's focus, and family physicians have always constituted the core of the NHSC's primary care and physician workforce. ${ }^{4,5}$ During its history, 5620 family physicians have served in the NHSC, including 703 who currently serve.

The NHSC's annual appropriation and, consequently, the size of its workforce have risen and fallen over the decades with Congress's fluctuating 
concern about the problem of health practitioner shortages and its willingness to apply public resources to the problem. ${ }^{4}$ But even during its 2 peak periods-at 3127 clinicians in 1986 and 4602 in 2005-the NHSC has never been sized to meet all practitioner shortfalls within Health Professional Shortage Areas (HPSAs), estimated at nearly 16,000 positions as of June 2009. ${ }^{3}$ There have long been calls for and goals set to expand the NHSC, ${ }^{6-8}$ including a recent joint call for expansion signed by leading family medicine, general internal medicine, pediatric, osteopathic, nursing, and dental organizations. ${ }^{9}$ But the funding has never been provided to allow the NHSC to expand significantly. Until this year.

February's American Recovery and Reinvestment Act (Public Law 111-5) ${ }^{2}$ included almost \$300 million in expansion funds for the NHSC, which will support an estimated 4200 additional practitioners and more than double the size of the NHSC's workforce. Bolstering the NHSC makes good sense within the Recovery Act, given the Act's goals to assist the unemployed and others weathering the current economic downturn, create new jobs, and stabilize local community infrastructure. ${ }^{2}$ Expanding the NHSC is also an important and necessary complement to the Recovery Act's \$500 million expansion of community health centers, ${ }^{2}$ for which NHSC-supported clinicians are a key component of staffing. ${ }^{10}$ Building the NHSC now also better prepares it for the central role it will probably play within health care reform initiatives. ${ }^{11,12}$

For the NHSC and its many supporters, this day has long been awaited. But sudden expansion will present challenges. Where will the additional applicants come from? How does a federal program with a dedicated but modest staff abruptly double the number of awards it makes and support twice the workforce in the field? And there is pressure to put Recovery Act funding to use immediately—for "shovel ready" projects-so that jobs are created now and secondary benefits to the economy can begin. Most NHSC awards with Recovery Act dollars therefore will have to be made this year, not next.

Leadership of the NHSC and its parent agency, the Health Resources and Services Administration, recognize this historic opportunity and its challenges, and they are responding quickly and creatively. In early June, Secretary of Health and Human Services Kathleen Sebelius announced that
\$200 million of the NHSC's Recovery Act funds are now available for thousands of new loan repayment awards. ${ }^{11}$ The need to make so many awards in the coming months has empowered the NHSC to make significant, timely improvements in its site eligibility designation processes for clinics and in its loan repayment application and award procedures for clinicians, remedying features of the program's operations that have previously challenged some applicants and sites. ${ }^{13}$ Newly announced changes ${ }^{14}$ include offering:

- More vacancies and choices of sites eligible for loan repayment. More than 7000 federally qualified health centers, designated rural health clinics, and other clinics already deemed eligible as loan repayment sites will now each be able to hire more clinicians who receive loan repayment. Previously, sites were limited to just a few loan payors at a time. In addition, more sites are being made eligible for loan repayment.

- Broadening the HPSA scores that allow a clinic to be eligible for loan repayment. Previously, loan repayment was available only to clinicians working in clinics that were in HPSAs estimated to have the greatest needs. Now, clinicians receiving loan repayment may work within any designated HPSA but with priority still given to HPSAs where need is greatest.

- Batch (rolling) admissions; first come, first served. For the first time, applications for loan repayment will be evaluated and prioritized continually, so that awards will be made on a first-come, firstserved basis. Previously, awards were made only once a year, a cycle that did not fit the timing needs of many clinicians' job searches. The goal now is to have applications processed and an award determination made within approximately 8 weeks all Recovery Act funds and allocated within 15 months.

- More application flexibility. Those interested in loan repayment no longer need to already be employed at an eligible site when they apply to the program. Clinicians looking for jobs can now know whether they will or won't receive loan repayment before committing to a practice. This change will allow clinicians to make more informed choices based on known pluses and minuses of each of the practices they are considering, making NHSC loan repayment a more effective recruitment tool. 
More information about the NHSC, the Loan Repayment Program and its recent changes, and eligible sites and jobs can be found at www.nhsc. hrsa.gov, www.nhsc.hrsa.gov/loanrepayment, and www.nhscjobs.hrsa.gov.

The NHSC's expanded offerings for loan repayment and changes streamlining the application process provide unprecedented opportunities for young, service-minded family physicians to fulfill dreams of a career, or perhaps just a few years, working in underserved communities. Changes broadening the number of sites eligible for loan repayment and number of awards allowed within each site increase chances that interested participants will find well-suited positions in communities that match their families' needs. We on the NHSC's National Advisory Council ${ }^{15}$ who have connections with family medicine hope that many family physicians will recognize and respond to this opportunity. This is a historic time for the NHSC and for its position and visibility among federal health care programs.

\section{References}

1. The White House, President Barack Obama. Service. Available at: http://www.whitehouse.gov/ issues/Service/. Accessed June 9, 2009.

2. U.S. Government Printing Office. Public Law 111-5. American Recovery and Reinvestment Act of 2009. Available at: http://www.gpo.gov/fdsys/pkg/ PLAW-111publ5/content-detail.html. Accessed June 8, 2009.

3. Health Resources and Services Administration, U.S. Department of Health and Human Services. HRSA Geospatial Data Warehouse. National Health Service Corps Details. Available at: http:// datawarehouse.hrsa.gov/nhscdetail.aspx. Accessed June 8, 2009.

4. Phillips RL, Fryer GE, Ruddy GR, McCann JL, Dodoo MS, Klein LS. Physician workforce: the special case of health centers and the National Health Service Corps. Am Fam Physician 2005;72:235.

5. The Robert Graham Center, Fryer GE, McCann JL, et al. Access, health and wealth: the impact of the National Health Service Corps in rural America, 1970-2000. Available at: http://www.grahamcenter.org/online/graham/home/publications/ monographs-books/2006/rgcmo-access-health.html. Accessed June 10, 2009.

6. Mullan F. The muscular Samaritan: the National Health Service Corps in the new century. Health Affairs 1999; 18:168-75.

7. Saxton JF, Johns MME. Grow the U.S. National Health Service Corps. JAMA 2009;301:1925-6.

8. Health Resources and Services Administration, U.S. Department of Health and Human Services. Fiscal year 2008 justification of estimates for appropriations committees. Details of performance analysis. Clinician recruitment and service. Available at: http://www.hrsa.gov/about/budgetjustification08/ ClinicianPerformanceAnalysis.htm\#NHSC. Accessed June 15, 2009.

9. National Health Service Corps Stakeholder Associations. [Letter to Director Orszag and Dr. Wakefield urging increased funding for the NHSC.] Available at: http://www.aamc.org/advocacy/library/ workforce/corres/2009/030409.pdf. Accessed June 8, 2009.

10. Rosenblatt RA, Andrilla CHA, Curtin T, Hart LG. Shortages of medical personnel at community health centers. Implications for planned expansion. JAMA 2006;295:1042-9.

11. U.S. Department of Health and Human Services. News Release: Secretary Sebelius makes Recovery Act funding available to bolster health care in needy communities, relieve providers' student debt. June 5, 2009. Available at: http://www.hhs.gov/news/press/ 2009pres/06/20090605a.html. Accessed June 10, 2009.

12. The Nation, Vanden Heuvel K, Kaufmann G. Revolutionizing primary healthcare. February 28, 2009. Available at: http://www.thenation.com/blogs/ edcut/412992. Accessed June 9, 2009.

13. American Association of Family Physicians, Arvantes J. AAFP News Now. HRSA official urges Title VII reauthorization, NHSC modernization. June 2, 2009. Available at: http://www.aafp.org/online/ en/home/publications/news/news-now/governmentmedicine/20090602hrsa-fmcc.html. Accessed June $15,2009$.

14. National Health Service Corps, Health Resources and Services Administration. Loan Repayment. Available at: http://nhsc.hrsa.gov/loanrepayment/. Accessed June 10, 2009.

15. National Health Service Corps, Health Resources and Services Administration. National Advisory Council. Available at: http://nhsc.hrsa.gov/about/ nac.htm. Accessed June 15, 2009. 